\title{
Henri Estienne, Introduction à la lecture de Sénèque (1586)
}

\section{Michele Mastroianni}

\section{Q OpenEdition \\ 1 Journals}

\section{Edizione digitale}

URL: http://journals.openedition.org/studifrancesi/9479

DOI: $10.4000 /$ studifrancesi.9479

ISSN: 2421-5856

\section{Editore}

Rosenberg \& Sellier

\section{Edizione cartacea}

Data di pubblicazione: 1 décembre 2007

Paginazione: 641

ISSN: 0039-2944

\section{Notizia bibliografica digitale}

Michele Mastroianni, «Henri Estienne, Introduction à la lecture de Sénèque (1586)», Studi Francesi

[Online], 153 (LI | III) | 2007, online dal 30 novembre 2015, consultato il 13 janvier 2021. URL: http:// journals.openedition.org/studifrancesi/9479; DOI: https://doi.org/10.4000/studifrancesi.9479

Questo documento è stato generato automaticamente il 13 janvier 2021.

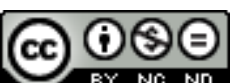

Studi Francesi è distribuita con Licenza Creative Commons Attribuzione - Non commerciale - Non opere derivate 4.0 Internazionale. 


\title{
Henri Estienne, Introduction à la lecture de Sénèque (1586)
}

\author{
Michele Mastroianni
}

\section{NOTIZIA}

HENRI ESTIENNE, Introduction à la lecture de Sénèque (1586), édition critique, texte et traduction par Denise CARABIN, Paris, Champion, 2007 («Textes de la Renaissance», 109), pp. 529.

1 Dopo la sua thèse su Les idées stoïciennes dans la littérature morales des $\mathrm{XVI}^{e}$ et XVII siècles (cfr. questi «Studi», 146, 2005) e la monografia sull'Ad Senecae lectionem Proodopoeia di Henri Estienne (cfr. questi «Studi», 152, 2007) Denise Carabin pubblica ora l'edizione critica, accompagnata da traduzione, di questa stessa opera di Estienne, così importante per ricostruire la fortuna di Seneca nel Cinquecento francese. Nella prima parte dell'opera, consacrata all'opera di Seneca filosofo stoico, Estienne dimostra la profondità del pensiero del moralista latino. Nella seconda parte affronta invece problemi retorici e di stile, confrontandosi peraltro con la stroncatura operata da Svetonio della lingua senecana, per contrastarla nell'apprezzamento di un linguaggio che «si iscrive in un processo di senso dinamico e nella fondazione di un'estetica della sospensione e della lettura intelligente». Henri Estienne non si limita, però, a un'analisi del testo di Seneca e a una esposizione dei suoi significati, ma offre un'opera di battaglia, in cui si scontra con gli umanisti del Cinquecento: soprattutto cerca polemicamente di screditare le edizioni degli imprimeurs rivali. Denise Carabin ci offre, dunque, accompagnato da una nitida traduzione, un libro fondamentale per penetrare nel laboratorio umanistico e soprattutto nei débats che lo hanno caratterizzato. 